\title{
A África subsaariana diante da pandemia de Coronavírus/COVID-19: difusão espacial, impactos e desafios
}

\author{
A África subsaariana diante da pandemia de Coronavírus/COVID-19: difusão \\ espacial, impactos e desafios \\ Sub-Saharan Africa facing the COVID-19 pandemic: spatial diffusion, impacts \\ and challenges \\ L'Afrique subsaharienne face à la pandémie de Coronavirus/COVID-19: diffusion \\ spatiale, impacts et enjeux \\ África subsahariana frente a la pandemia de coronavirus/COVID-19: difusión \\ espacial, impactos y desafíos
}

\section{Frédéric Monié}

\section{(2) OpenEdition}

Journals

Edição electrónica

URL: http://journals.openedition.org/espacoeconomia/13629

DOI: 10.4000/espacoeconomia.13629

ISSN: 2317-7837

Editora

Núcleo de Pesquisa Espaço \& Economia

Refêrencia eletrónica

Frédéric Monié, "A África subsaariana diante da pandemia de Coronavírus/COVID-19: difusão espacial, impactos e desafios », Espaço e Economia [Online], 18 | 2020, posto online no dia 22 abril 2020, consultado o 20 maio 2020. URL : http://journals.openedition.org/espacoeconomia/13629 ; DOI : https://doi.org/10.4000/espacoeconomia.13629

Este documento foi criado de forma automática no dia 20 maio 2020

(c) NUPEE 


\title{
A África subsaariana diante da pandemia de Coronavírus/ COVID-19: difusão espacial, impactos e desafios
}

\author{
A África subsaariana diante da pandemia de Coronavírus/COVID-19: difusão \\ espacial, impactos e desafios \\ Sub-Saharan Africa facing the COVID-19 pandemic: spatial diffusion, impacts \\ and challenges \\ L'Afrique subsaharienne face à la pandémie de Coronavirus/COVID-19: diffusion \\ spatiale, impacts et enjeux \\ África subsahariana frente a la pandemia de coronavirus/COVID-19: difusión \\ espacial, impactos y desafíos
}

\section{Frédéric Monié}

\section{Introdução}

No dia 13 de abril de 2020, a Organização Mundial da Saúde (OMS) informou que 1.739.007 pessoas de 213 países já tinham sido contaminadas pelo Coronavírus e que a COVID-19 já vitimou 108.432 doentes O Coronavírus 2019-nCOV é o agente da doença infecciosa respiratória Covid-19 (CoronaVIrus Disease-19) que se difundiu pelo mundo a partir de Wuhan (China), onde uma pneumonia atípica foi notificada no final de dezembro de 2019. Em fevereiro de 2020, observamos uma aceleração e uma globalização de sua difusão espacial através da rede mundial do transporte aéreo, cuja capilaridade e eficiência logística permite a priori propagar um vírus para qualquer lugar do Planeta em menos de 36 horas (Prevent Epidemics). A fase inicial de transmissão através dos territórios-rede transnacionais (HAESBAERT, 2020), ilustrativa do fenômeno de compressão do espaço-tempo (HARVEY, 1989), multiplicou os epicentros de contágio 
regionais, provavelmente a partir de plataformas aeroportuárias. Ou seja, estamos numa lógica de hubs and spokes onde a conectividade às redes logísticas globais constitui o ponto crítico da propagação do vírus. É somente quando o processo de difusão ingressa na sua fase comunitária que distância e proximidade se tornam variáveis críticas de maior relevância. Neste momento, medidas de contenção territorial e de confinamento são tomadas para romper a cadeia de transmissão nos territórios-zona (HAESBAERT, 2020). Além do gigantesco custo humano, a pandemia evidencia então a fragilidade e falhas de um processo de globalização econômica e comercial tido por muitos como exitoso e inexorável.

A crise atual, que testa os limites e capacidades de resiliência das sociedades e das economias, pode impactar dramaticamente a África subsaariana, onde os primeiros casos de contaminação foram oficialmente registrados nas metrópoles de Lagos (27/02/2020) e Dacar (03/03/2020). Governos e autoridades sanitárias do continente adotaram, quase imediatamente, políticas, medidas e protocolos de prevenção e tratamento semelhantes aos do resto do mundo. Nosso texto almeja analisar, em termos genéricos, alguns impactos prováveis da pandemia de Coronavírus/COVID-19 sobre as sociedades e economias da África subsaariana, onde a precariedade e a baixa capilaridade espacial dos sistemas de saúde pública constituem um motivo de preocupação maior frente ao avanço do vírus (partes 2,3 e 4). Mas, o período é também propício a debates e reflexões envolvendo intelectuais africanos que se mobilizam ativamente para pensar alternativas aos modelos de desenvolvimento, estruturas sociopolíticas e institucionais e relações entre a Humanidade e o Planeta impostos pela modernidade ocidental (parte 5). Antes, propomos uma análise da dinâmica geral da pandemia, de sua difusão espacial nas regiões e países subsaarianos e as pressões que ela exerce sobre os sistemas de saúde púbica (parte 1).

\section{1 - Coronavírus/COVID-19 na África subsaariana: dinâmica geral da pandemia, difusão espacial e pressões sobre os sistemas de saúde}

\section{A dinâmica geral da pandemia de Coronavírus/COVID-19 na África subsaariana}

O primeiro caso de Coronavírus na África subsaariana foi detectado em Lagos, capital econômica da Nigéria, e confirmado pelas autoridades sanitárias do país em 27/02 de 2020. A segunda notificação oficial de contaminação ocorreu em Dacar (Senegal) no dia 02 de março. Essas notificações tardias e o ritmo inicialmente lento da difusão do vírus geraram conjecturas e hipóteses que não consideravam características comuns a muitos fenômenos epidemiológicos. Em primeiro lugar, temos que ponderar que o número de casos de infecções começa a crescer de maneira exponencial após a fase de "importação" do vírus (através dos territórios-rede), quando a contaminação se torna comunitária (entre territórios-zonas). Ou seja, a África subsaariana não constitui, a priori, um ponto fora da curva. 


\section{EVOLUÇÃO DOS CASOS DE CORONAVÍRUS NO MUNDO}

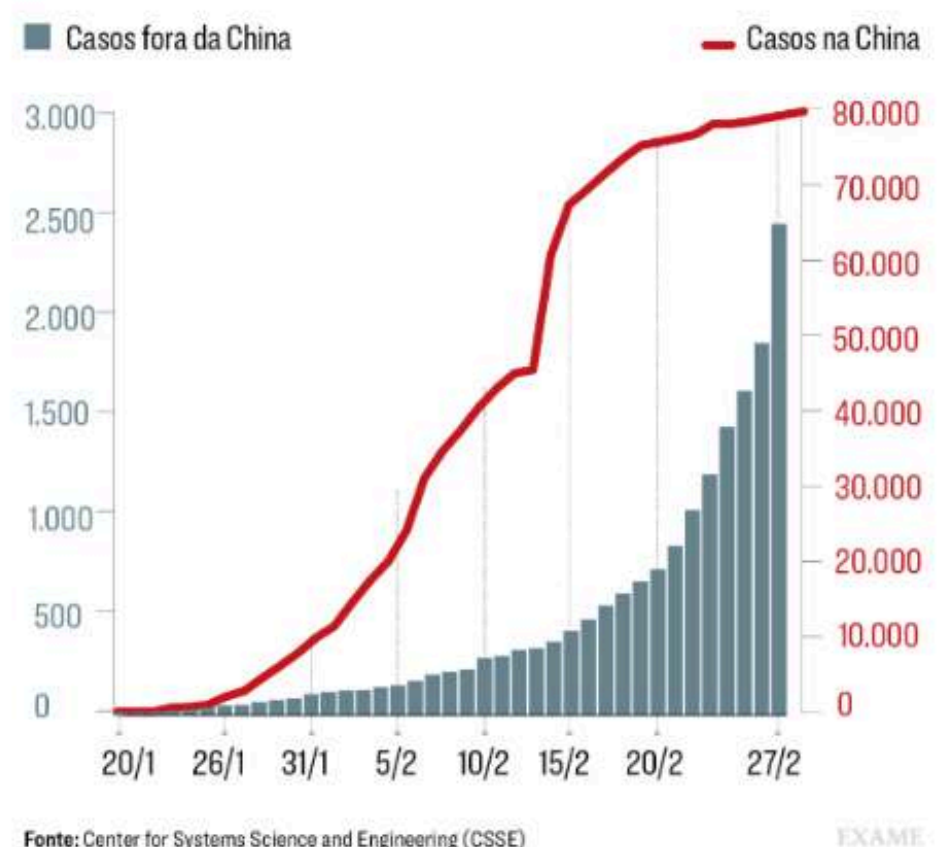

Fonte : Center for Systems Science and Engineering (CSSE)

Por seu lado, o caráter tardio dos primeiros casos foi inicialmente interpretado como o reflexo de condições climáticas especificas. Calor e elevada umidade do ar constituiriam escudos naturais freando a difusão socioespacial do vírus. Essa hipótese, sem embasamento científico, não leva em consideração que a diversidade dos biomas e dos climas no continente. Epidemiologistas africanos confirmam que, até o presente momento, nenhuma publicação científica comprovou essa afirmação. Da mesma maneira, a suposição que a difusão do Coronavírus na sociedade possa ser drasticamente limitada pelo contexto demográfico de um continente cuja população é majoritariamente jovem não considera que a proporção de jovens cujo sistema imunitário é debilitado pela prevalência de diversas doenças é muito superior à média mundial (FAYE, 2020)

o registro tardio dos primeiros casos de Coronavírus pode ser, ao nosso ver, a consequência de três fatores maiores. O primeiro é relacionado a existência de "desertos estatísticos" nas regiões mais conturbadas e/ou periféricas do continente (Somália, periferias de países do Sahel etc.) onde a precariedade das estruturas sanitárias e a insegurança se articulam da maneira mais dramática. 0 segundo fator diz respeito a carência de testes de detecção, que gera incertezas quanto a evolução real da pandemia. Vale aqui ressaltar que, num contexto de tensões no mercado mundial dos testes, as estratégias de governos asiáticos e ocidentais, firmas produtoras e atores das redes mercantis transnacionais geram tendências especulativas que prejudicarão gravemente os países mais pobres, em grande parte localizados na África. A terceira explicação é relacionada à baixa conectividade relativa da África subsaariana às cadeias de valor e às redes logísticas globais. Conforme ocorreu na ocasião da epidemia de SARS de 2002-2003, a lógica da difusão espacial global do vírus segue um padrão que poderia ser 
qualificado de centro/periferia. Os primeiros epicentros regionais da pandemia do Coronavírus/COVID-19 foram nós maiores das redes produtivas, logísticas e comerciais que estruturam o espaço global de fluxos: Wuhan, Beijing, Cingapura, Milão, Paris, Londres, Nova Iorque, São Paulo etc. O sistema mundial de transporte aéreo - 44.000 voos e 2,7 M. de passageiros por dia - constituiu o principal vetor de difusão do vírus nas escalas continental e intercontinental. Ou seja, antes da comunitarização da contaminação, a distância é uma variável secundária em relação a conectividade às redes logísticas. O gráfico seguinte, proposto Dirk Brockmann, da Humboldt University of Berlin, ilustra essa dinâmica (O'KEEFFE, 2020).

Gráfico 2- Modelo de difusão provável do Coronavírus a partir de Wuhan, elaborado por Dirk Brockmann

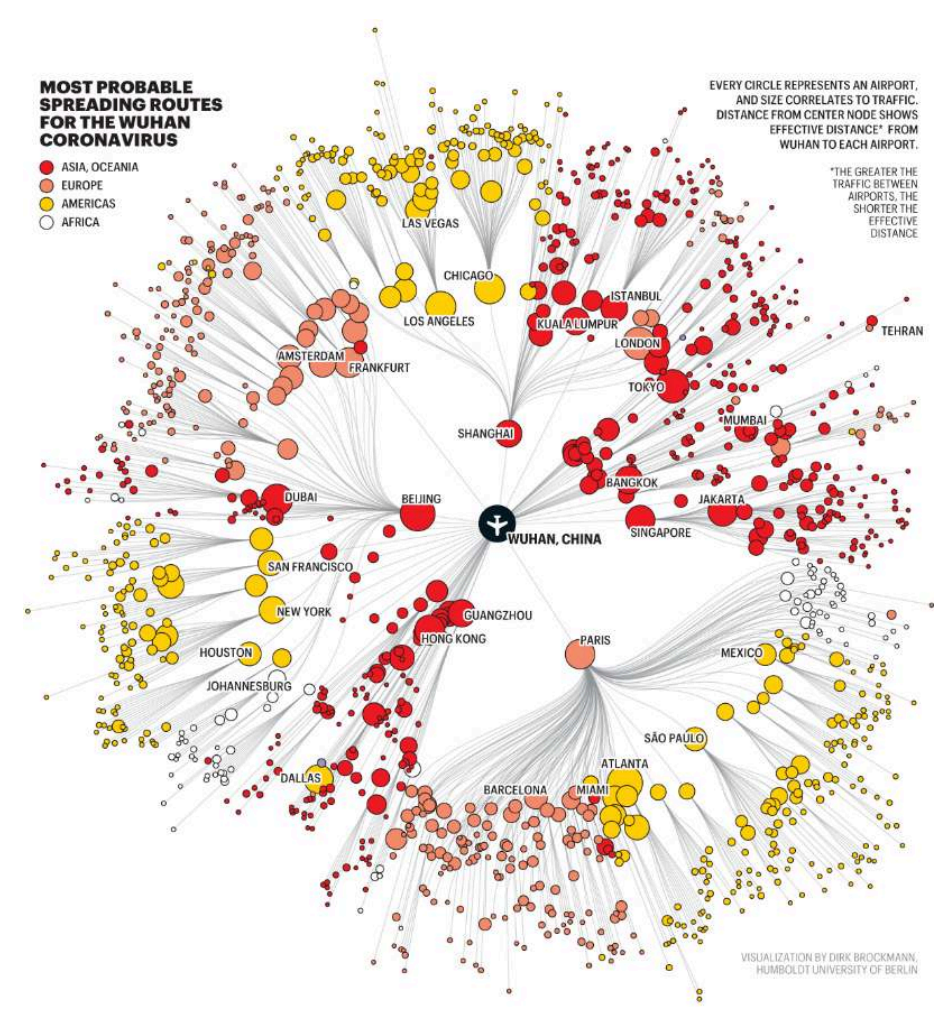

Fonte: O’KEEFFE (2020)

$\mathrm{Na}$ África austral, o aeroporto de Joanesburgo, hub regional da capital econômica da África do sul, constituiu provavelmente a principal porta de entrada do vírus na região, via Beijing. No caso da África ocidental, a modelização de Brockmann situa a plataforma aeroportuária de Paris, diretamente conectada à cidade de Wuhan que conta com montadoras francesas, como principal hub de difusão espacial do vírus em direção às capitais da região.

As métricas e mecanismos de difusão espacial do Coronavírus mudam, então, na fase comunitária da cadeia de transmissão, quando as interações interpessoais se firmam como principais vetores de contaminação nos territórios-zona (VELTZ, 1999; HAESBAERT, 2020). Conforme observado na Coreia do Sul, no nordeste da França e no norte da Itália aglomerações humanas em espaços de cultos e estádios podem ter acelerado a difusão local. Nesse caso, a variável distância se torna absolutamente relevante. Por isso, com base na observação da dinâmica da contaminação nos primeiros epicentros regionais, 
governos africanos adotaram muito cedo medidas de contenção territorial e de limitação da mobilidade. Mas, ao exemplo do que observamos no resto do mundo, as medidas não foram suficientes para romper a cadeia de transmissão e o número de notificações de indivíduos doentes do COVID-19, passou a crescer de maneira mais significativa a partir de meados de abril de 2020.

Gráfico 3 - Evolução diária do número de casos de COVID-19 no continente africano (01/03 a10-04/2020)

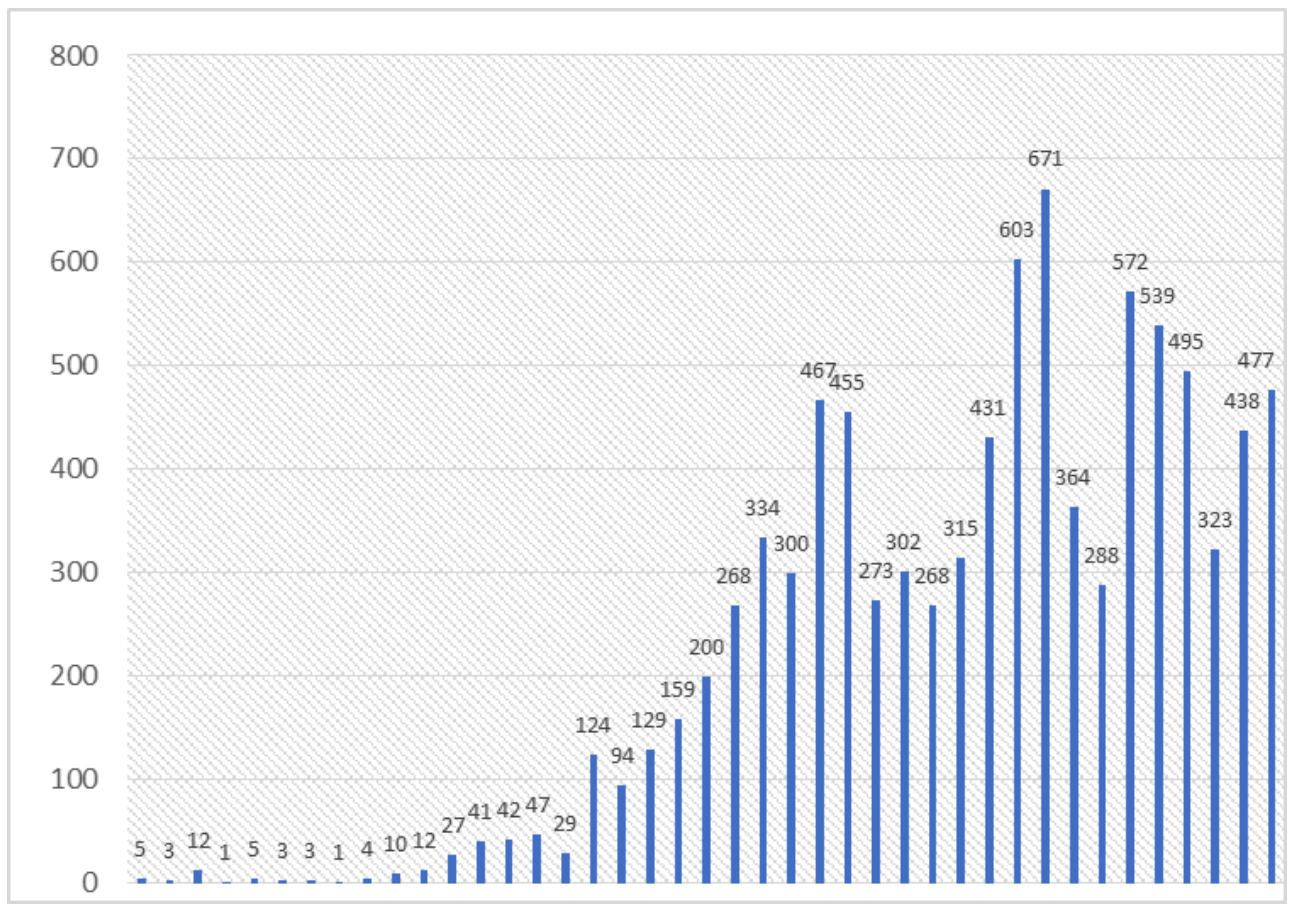

Fonte: https://amref.org/coronavirus/. Adaptado pelo autor.

\section{A distribuição geográfica dos casos de COVID-19 na África subsaariana}

$\mathrm{Na}$ escala da África subsaariana, é difícil evidenciar um padrão claro de difusão da pandemia de Coronavírus/COVID-19 (mapa 1). A República sul-africana é, de longe, o país mais atingido da região. Mas, é também um dos que mais testa sua população. Por sua parte, o "Arco" Costa do Marfim-Gana/Níger também apresenta um nível elevado de contaminação. Podemos, nos casos de Gana e Costa de Marfim extrapolar que estruturas sanitárias menos precárias permitiriam limitar os casos de subnotificação? No caso do "Triângulo" Camarões-Costa do Marfim-Níger, podemos sugerir que a intensidade das interações espaciais transfronteiriças internas à zona CFA ou entre a Zona CFA e a Nigéria, possa explicar em parte o elevado nível de casos registrado? 
Mapa 1 - Casos confirmados de COVID na África Subsaariana

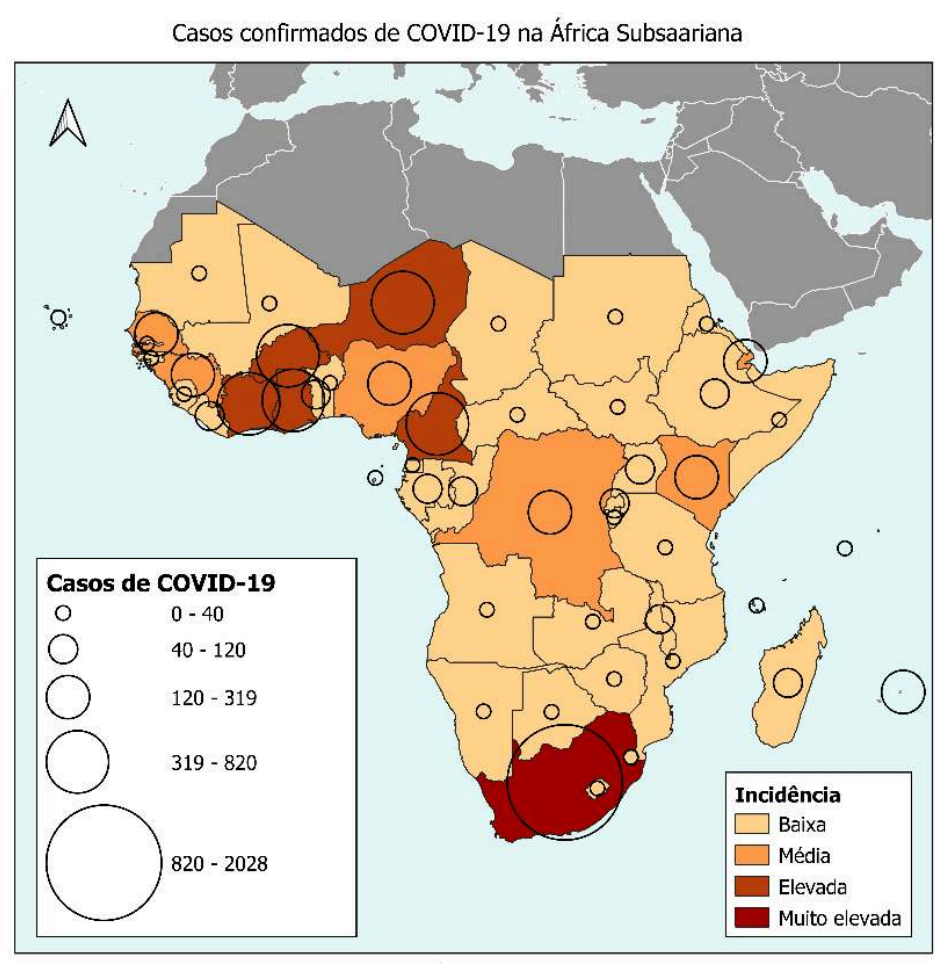

Fonte: Casos confirmados da Organização Mundial da Saúde em 11 de abril de 2020.

Elaboração: Cayo Franco (2020)

Tabela 1 - Coronavírus/COVID-19 África subsaariana (12/04/2020)

\begin{tabular}{|l|l|l|l|}
\hline País & Casos & Casos por M. de hab. & óbitos \\
\hline África do Sul & 2.028 & 34,5 & 25 \\
\hline Angola & 19 & 0,61 & 2 \\
\hline Benin & 35 & 2,98 & 1 \\
\hline Botsuana & 13 & 5,56 & 1 \\
\hline Burkina Faso & 484 & 23,19 & 27 \\
\hline Burundi & 5 & 0,46 & 0 \\
\hline Cabo Verde & 8 & 14,53 & 1 \\
\hline Camarões & 820 & 30,89 & 12 \\
\hline Chade & 11 & 0,68 & 0 \\
\hline Congo & 60 & 10,87 & 5 \\
\hline Costa do Marfim & 533 & 20,64 & 4 \\
\hline
\end{tabular}




\begin{tabular}{|c|c|c|c|}
\hline Djibouti & 187 & 173,41 & 2 \\
\hline Eritreia & 34 & 9,72 & 0 \\
\hline Etiópia & 71 & 0,72 & 3 \\
\hline Gabão & 49 & 22,55 & 1 \\
\hline Gâmbia & 9 & 3,83 & 1 \\
\hline Gana & 408 & 13,47 & 8 \\
\hline Guiné & 250 & 20,46 & 0 \\
\hline Guiné Equatorial & 21 & 15,46 & 0 \\
\hline Guiné-Bissau & 38 & 23,68 & 0 \\
\hline Ilhas Maurício & 319 & 251,98 & 9 \\
\hline Libéria & 48 & 10,73 & 5 \\
\hline Madagascar & 102 & 3,89 & 0 \\
\hline Malawi & 12 & 0,63 & 2 \\
\hline Mali & 87 & 4,36 & 7 \\
\hline Mauritânia & 7 & 1,72 & 1 \\
\hline Moçambique & 21 & 0,7 & 0 \\
\hline Namíbia & 16 & 6,51 & 0 \\
\hline Níger & 491 & 22 & 11 \\
\hline Nigéria & 318 & 1,54 & 10 \\
\hline Quênia & 197 & 4,14 & 8 \\
\hline Rep. Centro-Africana & 8 & 1,46 & 0 \\
\hline Rep. Dem. do Congo & 234 & 2,61 & 20 \\
\hline Ruanda & 120 & 9,7 & 0 \\
\hline Senegal & 280 & 17,27 & 2 \\
\hline Serra Leoa & 10 & 1,27 & 0 \\
\hline Seychelles & 11 & 112,68 & 0 \\
\hline Somália & 21 & 1,32 & 1 \\
\hline
\end{tabular}




\begin{tabular}{|l|l|l|l|}
\hline Suazilândia & 14 & 12,81 & 0 \\
\hline Sudão & 19 & 0,45 & 2 \\
\hline Sudão do Sul & 4 & 0,31 & 0 \\
\hline Tanzânia & 32 & 0,57 & 3 \\
\hline Togo & 76 & 10,08 & 3 \\
\hline Uganda & 53 & 1,32 & 0 \\
\hline Zâmbia & 40 & 2,24 & 2 \\
\hline Zimbábue & 14 & 0,92 & 3 \\
\hline
\end{tabular}

Fonte: Organização Mundial da Saúde (OMS). Organização: F. Monié

Considerando o número de casos de Coronavírus/COVID-19 reportado à população, nota-se que a percentagem dos habitantes contaminados é muito superior à média em três (pequenos) países:

- as ilhas Mauricio e Seicheles, que são integradas às redes turísticas mundiais por densas conexões aéreas, apresentam maior nível de desenvolvimento humano e dispõem estruturas sanitárias suscetíveis de detectar os casos;

- Djibuti, nota-se um elevado número de casos que contrasta com a ausência de mortes pelo COVID-19. Emitimos a hipótese que a existência de bases militares (França, China, Estados Unidos, Japão e Itália) (MARTINEAU, 2018) dispondo de equipamentos sanitários sofisticados pode facilitar a detecção e a hospitalização das pessoas contaminadas. Neste caso, estamos diante do paradoxo de um país funcionando como hub militar e estratégico mundial (lógica exógena), mas cuja sociedade mantém interações pouco densas com os países vizinhos (Chifre da África, cone sul da Península arábica) (lógica endógena).

\section{A difusão espacial em nível infranacional}

As grandes cidades constituem os epicentros da atual crise pandêmica, além de se posicionar como vetores de difusão do vírus para o interior dos territórios nacionais. Elas combinam um conjunto de características favoráveis a transmissão do Coronavírus.

As infraestruturas de transporte que conectam as metrópoles africanas à malha circulatória continental e global constituíram a porta de entrada do vírus. Quando ingressamos na fase de difusão comunitária, alguns fatores se tornam críticos. A densidade populacional, que estimula as interações de proximidade, constitui um terreno fértil para o contágio, em particular nas favelas e loteamentos. Em Nairóbi, capital do Quênia onde os dois terços da população se aglomeram em $6 \%$ do território urbano (HAAS, 2020), a estrutura particularmente desigual da organização do espaço urbano expõe de maneira cruel a vulnerabilidade social e sanitária dos mais pobres. 
Foto 1 - Favela de Kibera e campo de Golfe, Nairóbi, Quênia

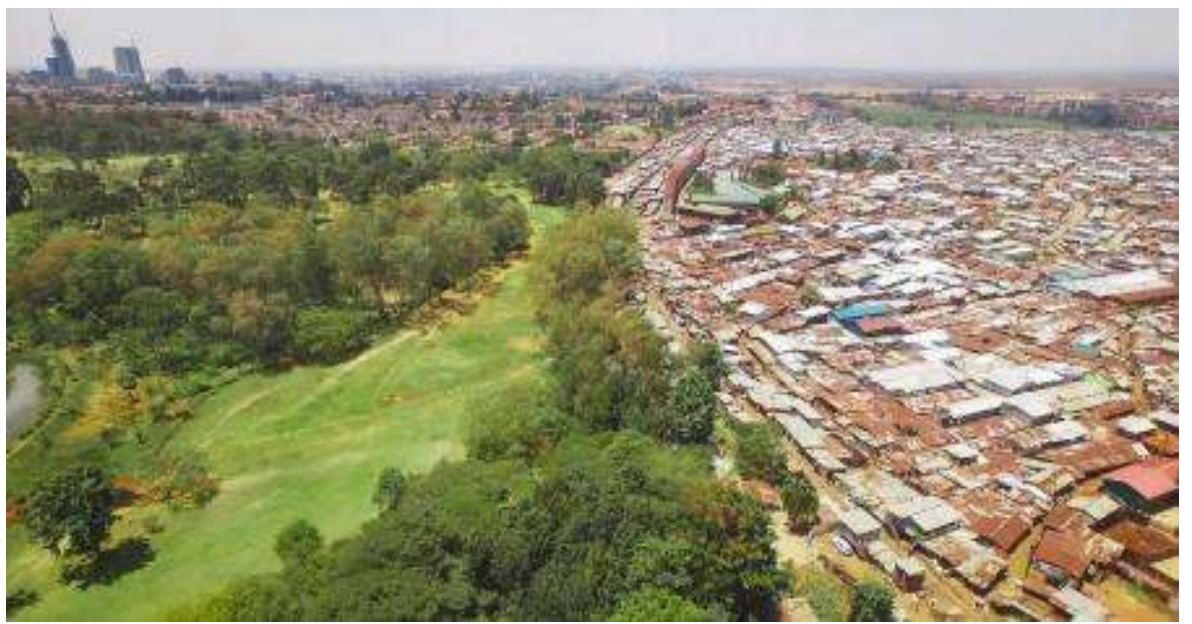

Fonte: Johnny Miller/Thomson Reuters Foundation in Kuo (2016)

Em escala micro, a ausência de políticas habitacionais atendendo à demanda (pouco solvável) da maioria da população provoca fenômenos de superlotação das unidades residenciais que maximizam o risco sanitário. Em Kampala (Uganda), 71\% das famílias dormem, por exemplo, num mesmo cômodo (HAAS, 2020). Cabe, no entanto, ressaltar que a metrópole providencia, também, a maior e melhor densidade de estruturas sanitárias. A capital ugandesa concentra, assim, $80 \%$ dos leitos de UTI do país (HAAS, 2020).

Por sua parte, a difusão espacial do Coronavírus/COVID-19 em escala infranacional parece obedecer a um padrão clássico, caracterizado por uma relativa correlação entre número e/ou proporção de casos e hierarquia urbana. Ou seja, o número de casos é, em termos genéricos, relativo ao tamanho das cidades (POUYA, 2020). A situação da cidade na malha circulatória do país deve, em alguns casos, ser levada em consideração. É, por exemplo, o caso de Bobo-Dioulasso, 2a maior cidade de Burquina Fasso, lugar central na economia regional das trocas comerciais além de ser um nó maior de conexão rodoviária e ferroviária com países vizinhos (Mali, Costa do Marfim). 


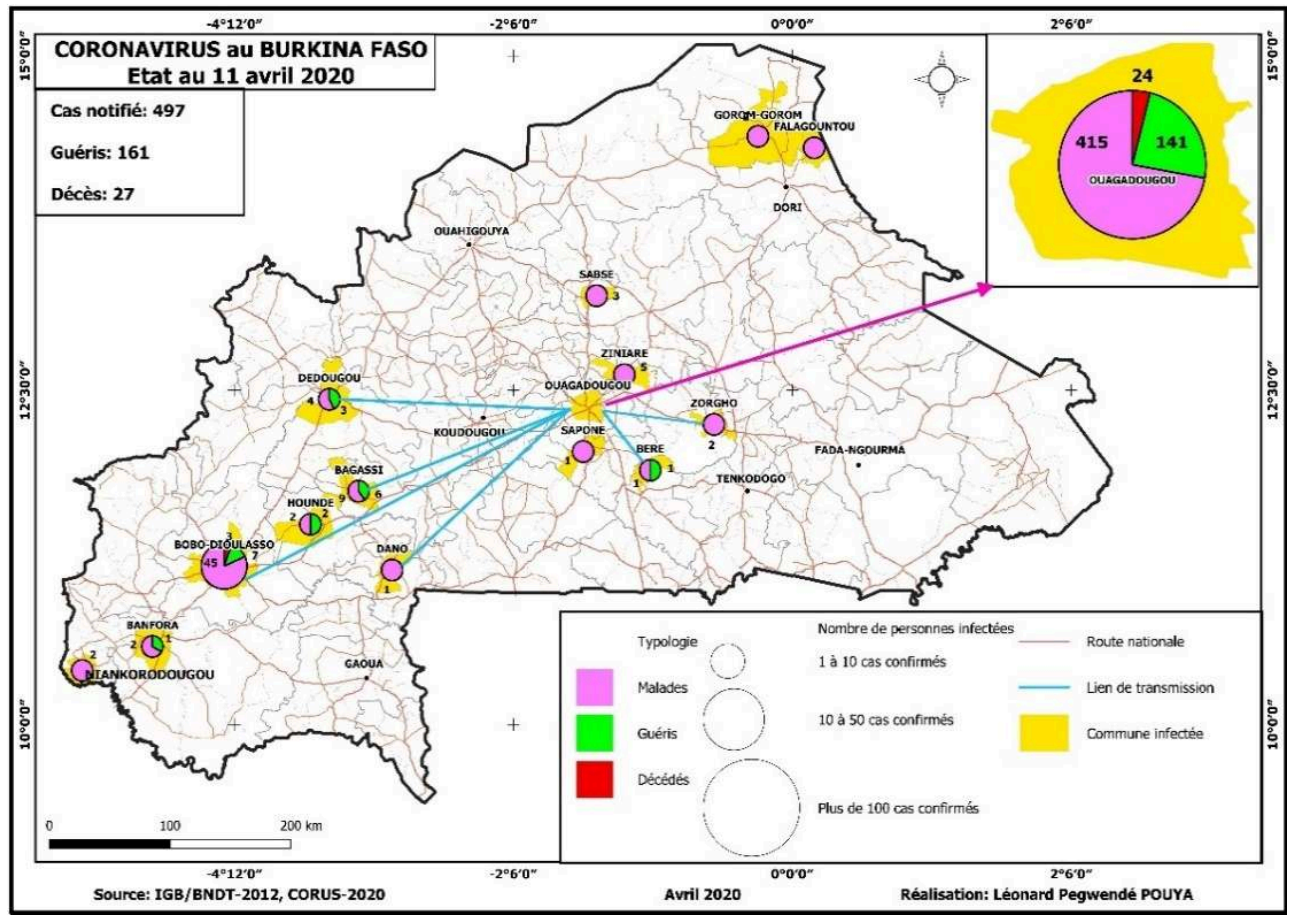

Organização e realização: Bouya (2020)

Em nível local, uma interrogação persiste a respeito da situação sanitária dos sítios extrativistas, em particular no Sahel, no Leste do Congo, na República Centro-africana e em Madagascar, onde os espaços de extração, informais ou pouco regulados, de minérios, pedras semipreciosas e ouro constituem potenciais pontos de difusão local do vírus (CABALLERO, 2017; YONLIHINZA, 2017). Elevada densidade de trabalhadores, prevalência de patologias como malária ou silicose, ambientes institucionalmente desregulados, estruturas sanitárias precárias, presença de população flutuante e baixíssimo nível de proteção social expõem os trabalhadores aos efeitos da pandemia. Em Burquina Fasso, os sítios auríferos foram, por exemplo, epicentros de contaminação comunitária (POUYA, 2020). No caso do extrativismo de grande porte, as multinacionais africanas e estrangeiras ao continente estruturam suas operações em sítios produtivos e vetores de transporte eficientemente conectados às redes dos mercados de commodities (MONIÉ, 2012). Os enclaves produtivos (plataformas petrolíferas, minas etc.) são expostos de maneira paradoxal a pandemia: os trabalhadores qualificados estrangeiros circulam nos territórios redes do arquipélago econômico mundial (VELTZ, 1999), sendo, portanto, sujeitos a contaminação nas plataformas aeroportuárias mundiais. Por sua parte, a vida no interior do enclave é estruturalmente confinada em relação a um fora apreendido com um espaço de riscos para os corpos protegidos (MONIÉ, 2012). Os enclaves, territórios-zona que têm a capacidade de modular suas interações com os espaços contíguos em função de riscos ambientais, sociais e geopolíticos, devem administrar o dilema de sua inserção nos circuitos logísticos mundiais e de seu abastecimento em produtos básicos, sendo eles importados ou locais (MONIÉ, 2012). Considerando o peso econômico do extrativismo na África subsaariana, as estratégias das corporações frente a pandemia impactaram a conjuntura de muitas economias nacionais. 


\section{As pressões sobre os sistemas de saúde pública no contexto da pandemia de coronavírus}

Segundo Vera Songwe, da Comissão Econômica das Nações Unidas para a África, poucos países da África subsaariana (África do Sul, Senegal, Quênia, Costa do Marfim etc.) dispõem de infraestruturas sanitárias adequadas (TISSOT, 2020). As sociedades se deparam com sistemas de saúde globalmente precários e de baixa capilaridade espacial. Em termos globais, avalia-se que mais da metade da população não tem acesso à serviços de saúde e de bem-estar social adequados: precariedade dos estabelecimentos e dos equipamentos, carência de material e remédios, falta de leitos e de unidades de terapia intensiva (UTI), dificuldades de acesso etc. Estima-se que os sistemas de saúde operam à $49 \%$ de sua capacidade (GÓMEZ DÍAZ; CRUZ MATA, 2020). É nas áreas rurais ( $60 \%$ da população) e na periferia das grandes cidades que a situação é mais crítica, ao exemplo do que ocorre em outras regiões do mundo. A situação pode, por exemplo, se tornar dramática para os 5 milhões de habitantes da República Centro Africana que teriam somente três respiradores artificiais à disposição. No Sudão do Sul, considerado o país mais vulnerável do continente pelo Africa Center for Strategic Studies, um único hospital, localizado na capital Juba, se dedica ao tratamento de doenças infeciosas, com 10 respiradores artificiais e cerca de 30 leitos a disposição dos 14 milhões de habitantes do país.

Essa precariedade dos sistemas de saúde se deve a fatores estruturais e conjunturais. Nas décadas de 1990 e 2000, a adoção de Programas de Ajuste Estrutural (PAS) e do receituário neoliberal do Consenso de Washington, impostos aos países mais endividados pelas agências internacionais, se traduziu por uma queda dos investimentos em bem-estar social. Deve-se considerar também que as elites africanas costumam resolver seus próprios problemas de saúde recorrendo à estabelecimentos hospitalares privados na Península arábica, em Israel e, sobretudo, na Europa ocidental.

No que diz respeito a detecção, graças ao esforço conjugado da União Africana e do Instituto Pasteur de Dacar (Senegal), o número de países dispondo de centros habilitados passou de 2 para 48 desde o mês de fevereiro de 2020 (GÓMEZ DÍAZ; CRUZ MATA, 2020). No entanto, as tensões geopolíticas no mercado mundial dos testes, das máscaras, das luvas, do cloro etc. submetido à exacerbação dos nacionalismos econômicos e à práticas especulativas por parte dos produtores e consumidores, podem prejudicar gravemente a capacidade de resposta dos governos africanos frente ao avanço da pandemia. 
Foto 2 - Vendedor de máscaras em Brazzaville (Rep. Do Congo)

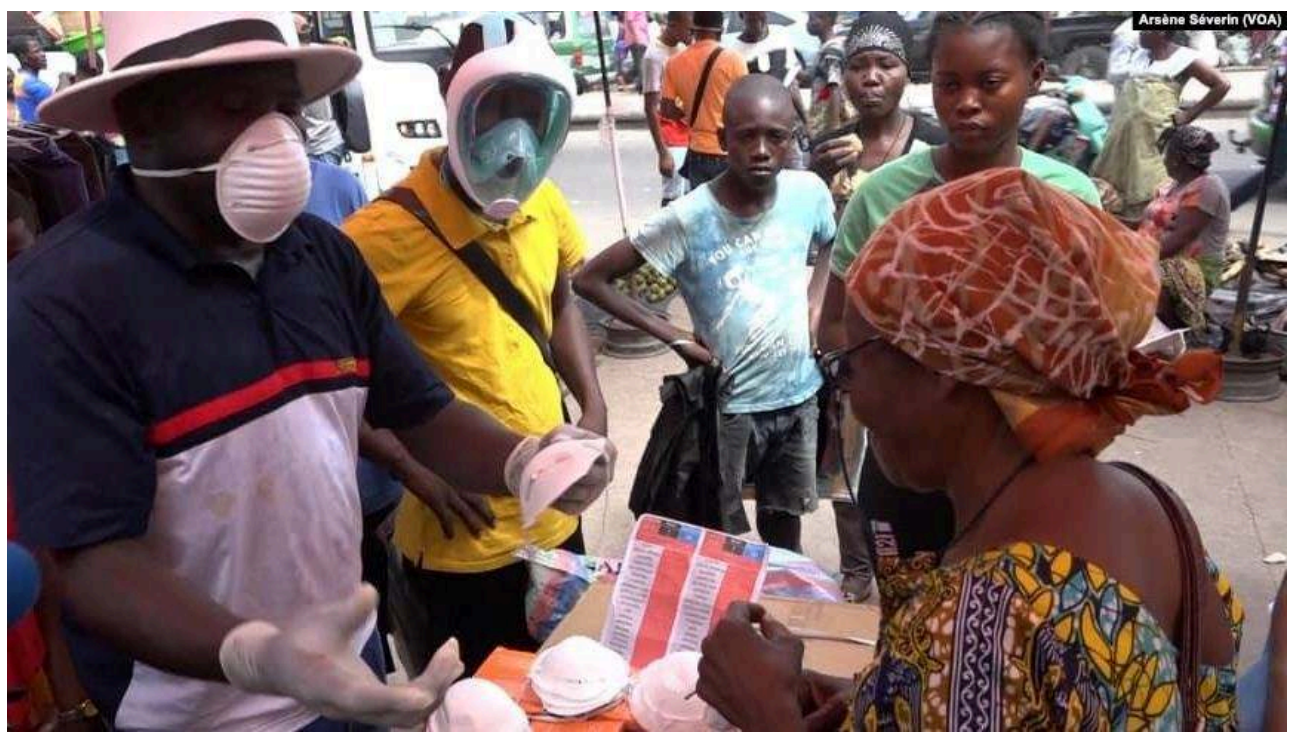

Foto: VOA/Arsène Séverin

A pandemia do Coronavírus pode também prejudicar os programas de luta contra doenças e epidemias preexistentes (tuberculose, sarampo, malária etc.) suscetíveis de perder parte dos recursos financeiros que lhe são atribuídos por governos e Organizações Não Governamentais (ONGs). A epidemia de Ebola tinha, por exemplo, restringido o acesso às redes de saúde pública e prejudicado as campanhas de vacinação infantil em Serra Leoa (SUN; SAMBA; YAO et al, 2017). Teme-se, também, que os sucessos recentes registrados na luta contra a malária (inseticidas, fumigação, tratamento precoce etc.) sejam parcialmente colocados em xeque (GÓMEZ DÍAZ; CRUZ MATA, 2020)

Mesmo com o aumento da capacidade infra-estrutural e técnica de resposta à expansão da pandemia, as autoridades sanitárias deverão lidar com a carência estrutural de recursos humanos, exacerbada pelo êxodo de trabalhadores qualificados. 0 número de médicos e enfermeiras ganenses é, por exemplo, maior na Grã-Bretanha do que no país de origem, expondo uma face cruel do brain drain. Na Costa do Marfim, menos de 200 pessoas dispõem de uma formação em reanimação. Considerando que a exposição dos profissionais da saúde à doentes do Covid-19, o ponto de ruptura no atendimento aos pacientes pode ser alcançado a curto prazo em caso de crescimento exponencial do número de casos entre enfermeiras e médicos.

Outra questão diz respeito ao acesso às vacinas e remédios. Num continente onde entre 70 e $90 \%$ dos medicamentos são importados e frequentemente caros, o baixo poder aquisitivo da maioria da população estimula o recurso à produtos falsificados, produzidos localmente ou importados. Além disso, a África é uma região onde redes mercantis ilegais escoam remédios originais próximos do vencimento ou já vencidos. $O$ desenvolvimento de uma indústria farmacêutica endógena, ainda incipiente, é, portanto, estratégico para alcançar mais segmentos da população. 
Gráfico 4 - Apreensões de remédios falsificados entre 2013 e 2017 (em \%)
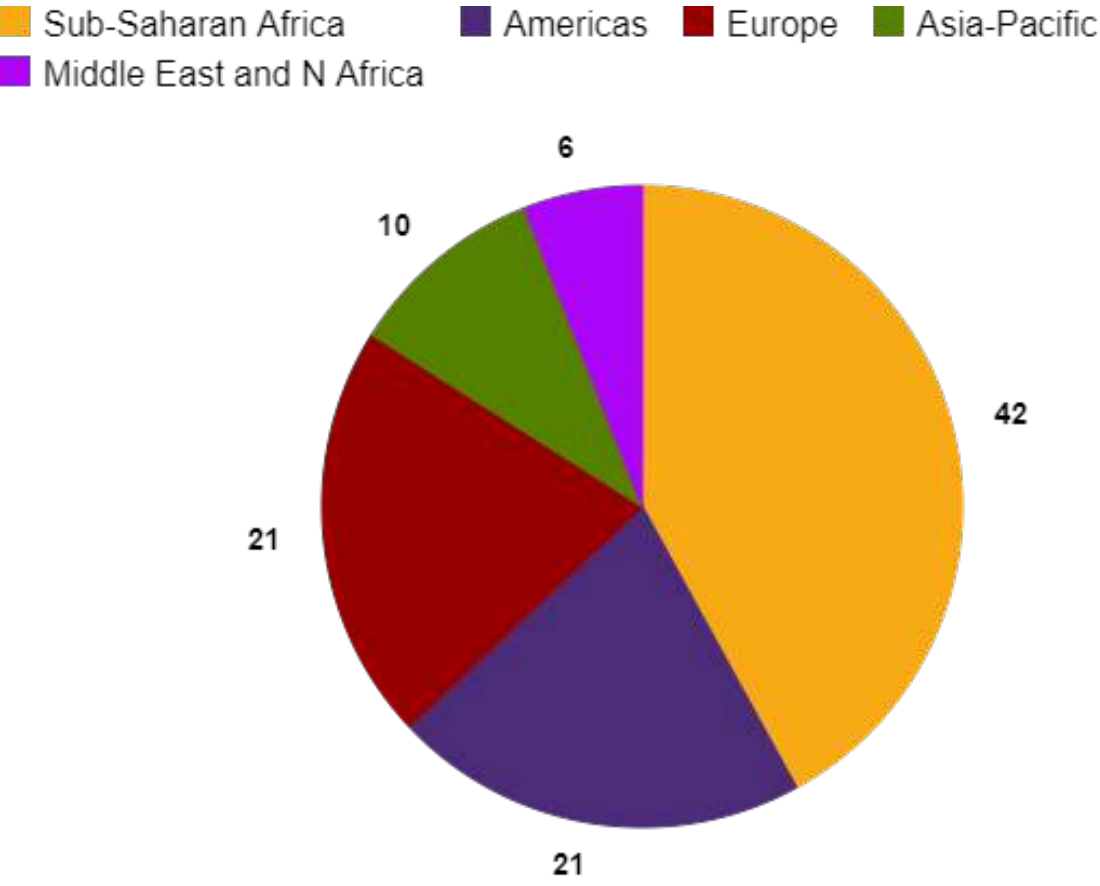

Fonte: OMS Data

Segundo a pesquisadora queniana Jenniffer Mabuka-Maroa, da African Academy of Sciences, as instituições de pesquisa devem também lidar com a escassez de testes clínicos. No dia 26 março de 2020, entre os 87 testes envolvendo vacinas e remédios em curso no mundo, nenhum era realizado na África subsaariana (MABUKA-MAROA, 2020). A ausência do mapa mundial dos testes clínicos é problemática considerando a necessária diversidade genética dos protocolos de pesquisa e desenvolvimento (MABUKA-MAROA, 2020). Para Mabuka-Maroa, a escassez de recursos financeiros em nível nacional deve estimular a cooperação transnacional seguindo uma lógica de hub and spokes permitindo aos laboratórios mais bem equipados de manter interações permanentes com estruturas de menor porte (MABUKA-MAROA, 2020).

A capacidade de resposta do sistema de saúde é, enfim, tributária de fatores geopolíticos. No Sahel (Mali, Burquina Fasso, Níger), na Somália, na República Centro Africana ou no Leste da República Democrática do Congo, o contexto geopolítico conturbado prejudica a coordenação das escalas de governança dos sistemas nacionais de saúde pública e o acesso seguro à todas as regiões do território nacional. No Norte do Mali, o Comité Internacional da Cruz Vermelha aponta que 93\% das estruturas sanitárias foram destruídas pelo conflito em curso. 0 acesso às distantes instalações do Sul país é oneroso e inseguro demais para a maioria da população. No Burquina Fasso, Pouya (2020) relata que os conflitos no Leste do país provocaram um afluxo de deslocados em cidades médias cujas capacidades sanitárias já beiram a saturação.

\section{2 - As políticas e medidas de luta contra o Coronavírus na África subsaariana}

Considerando a precariedade dos sistemas e equipamentos de saúde pública de muitos países, governos africanos levaram imediatamente em consideração que um aumento 
exponencial dos casos de Covid-19 geraria uma situação de colapso nos centros de saúde e estabelecimentos hospitalares. Objetivando romper a cadeia de transmissão do vírus, as autoridades agiram rapidamente no sentido de limitar as aglomerações de pessoas em lugares públicos, de popularizar gestos barreira, de promover o distanciamento social, além de adotar medidas de contenção territorial (controle mais rígido das fronteiras terrestres, limitação do tráfego aéreo etc.). 0 governo burquinabé decretou, por exemplo, o estado de emergência sanitária, um toque de recolher aplicado ao território nacional entre $19 \mathrm{~h}$ e $05 \mathrm{~h}$ e o fechamento de todas as fronteiras à circulação de pessoas (POUYA, 2020).

As políticas, medidas e protocolos adotados na luta contra a pandemia de Coronavírus/ COVID-19, são, no entanto de difícil aplicação. As campanhas de prevenção devem compor com o fato que $40 \%$ da população da África subsaariana não têm acesso direto à água limpa, o que dificulta a adoção das medidas de higiene pessoal básicas suscetíveis de frear a contaminação. No Sudão do Sul, somente $34 \%$ dos lares conseguem acesso a um poço ou uma pia coletiva em menos de 30 minutos. A adoção de gestos barreiras, como a limpeza regular das mãos usando sabão e álcool em gel, enfrenta também a dupla problemática da penúria de produtos e do baixo poder aquisitivo da maioria da população.

As políticas de prevenção e as ações de luta contra a difusão social e espacial do Coronavírus enfrentam outro dilema maior. 0 combate à contaminação local se depara com seu impacto dramático sobre os trabalhadores dos circuitos inferiores da economia urbana, numa região do mundo onde o setor informal, seja ele rural ou urbano, emprega a grande maioria da mão-de-obra (SANTOS, 1979; 1965). O dilema entre sobrevivência sanitária e biológico se impõe de maneira dramática às populações mais pobres, como em Kampala (Uganda), onde 93\% dos trabalhadores do setor informal vivariam abaixo do nível da pobreza (HAAS, 2020). Os governos adotarão programas visando a mitigar os impactos sociais da pandemia? Qual a capacidade de adaptação à crise atual das redes comunitárias (familiares, religiosas, de linhagem etc.) que costumam garantir um mínimo de bem-estar em contextos conturbados?

Por sua parte, as medidas de contenção territorial são, também, questionadas por intelectuais, como Ibrahim Assane Mayaki (Níger), Diretor executivo da Secretaria do New Partnership for Africa's Development (NEPAD), que adverte que o fechamento das fronteiras é suscetível de desorganizar circuitos transnacionais informais de abastecimento em alimentos e agravar a situação alimentar e sanitária nas regiões periféricas de alguns países (TILOUINE, 2020).

\section{3 - Os impactos da pandemia de Coronavírus sobre as economias subsaarianas}

Ao longo do período 2000/2014, a trajetória das economias africanas tem sido caracterizada por um ritmo de crescimento do PIB superior à média mundial. Desde então, observamos uma desaceleração da expansão econômica, que afeta particularmente os países exportadores de petróleo e de minérios, além de um forte aumento do nível do endividamento público. Fica também patente que, salvo exceções como Etiópia, Ruanda ou Senegal, a tão protelada inserção competitiva na globalização não estimulou a diversificação de economias que seguem dependentes das exportações de um pequeno número de bens primários. No campo social, apesar de progressos do 
IDH, o modelo de desenvolvimento intensificou as desigualdades e gerou pouco emprego formal. Neste contexto, os efeitos da pandemia do Coronavírus/COVID-19 podem se revelar dramáticos.

\section{Os possíveis efeitos macroeconômicos}

Os efeitos da crise do Coronavírus/COVID-19 não serão homogêneos considerando a diversidade das estruturas das economias. Além disso, a contaminação pode afetar desigualmente regiões e países do continente. No entanto, algumas características invariáveis permitem identificar e analisar alguns dos efeitos genéricos da pandemia sobre as economias. Num estudo recente, a União Africana desenhou dois cenários avaliando os possíveis impactos macroeconômicos da pandemia sobre o continente (incluindo a África do Norte). O cenário mais otimista prevê uma pandemia se estendendo até julho de 2020 e afetando "moderadamente" os diversos países. Por sua parte, o cenário mais pessimista antecipa que a pandemia se estenderia até agosto, impactando mais duramente o continente. O crescimento econômico seria respectivamente de $-0,8 \%$ e $-1,1 \%$, contra previsões iniciais de $+3,4 \%$ (AFRICAN UNION, 2020).

Na escala da África subsaariana, um relatório do Banco Mundial antecipa um cenário recessivo brutal. Os economistas da instituição preveem uma queda do PIB oscilando entre -2,1 e -5,1\% em 2020, caracterizando, assim, a primeira recessão desde o final da década (perdida) de 1990 (WORLD BANK, 2020). A combinação de fatores como a desorganização dos circuitos produtivos e comerciais, a queda dos Investimentos Diretos Externos (IDE) e outros fluxos financeiros (ajuda internacional, remessas de trabalhadores migrantes, receitas do turismo etc.), os impactos microeconômicos do confinamento e das restrições à circulação etc. deveria provocar entre 37 e 79 bilhões de dólares de perdas de produção (WORLD BANK, 2020).

A forte desaceleração do crescimento dos principais parceiros comerciais, com destaque para a China e a Zona Euro, deve impactar os países africanos mais integrados às redes do comércio mundial de commodities. O estudo da União Africana (2020) antecipa uma queda de $35 \%$ das trocas comerciais internacionais para o conjunto do continente. Entre os países mais afetados figuram os exportadores de petróleo (Nigéria, Angola, Chade, Guiné Equatorial, Sudão do Sul, República do Congo). A renda das exportações desses países já tinha sido impactada pela queda do preço do barril decorrente da guerra comercial entre Arábia Saudita e Rússia. Estima-se que as perdas para a Nigéria, onde o petróleo representa $91 \%$ do valor das exportações, podem alcançar 19 bilhões de dólares. Os cortes no orçamento de 2020, elaborado com base num preço médio do barril de 57 dólares, podem se revelar dramáticos para a população. Considerando que a atual crise sanitária deve se traduzir, a médio prazo, por uma queda da demanda e do preço do petróleo e do gás natural, a diminuição dos fluxos dos investimentos pode prejudicar a execução de grandes projetos petrolíferos na Angola e colocar em risco os megaprojetos na cadeia do gás natural na Bacia de Rovuma (norte de Moçambique).

Países onde o turismo internacional representa uma importante fonte de divisas (África do Sul, Quênia, Cabo Verde etc.) são também fortemente impactados pela queda da demanda. Os economistas da União Africana evocam perdas de aproximadamente 2 milhões de empregos e 50 bilhões de dólares de receitas (AFRICAN UNION, 2020). As maiores companhias aéreas do continente já estão acumulando déficits financeiros. No 
dia 07 de abril de 2020, as perdas da Ethiopian Airlines, maior companhia africana, já tinham ultrapassando 550 milhões de dólares. A recuperação do setor do turismo, que vinha se expandindo nos últimos anos, pode demorar vários anos.

Se as economias especializadas na produção e na exportação de bens primários e as regiões turísticas são particularmente expostas aos efeitos da pandemia, o país suscetível de sofrer o maior impacto macroeconômico é paradoxalmente a África do Sul. o país, que já apresentava sinais de recessão desde o 2.ํ semestre de 2019, não será protegido pelo seu tecido econômico mais diversificado e seu mercado doméstico mais desenvolvido (WORLD BANK, 2020). A retração da produção industrial (indústria automobilística, agroalimentar, química etc.), do comercio, do turismo interno e internacional constituem motivos suplementares de inquietação para o governo sulafricano.

Por sua parte, países menos dependentes das exportações de commodities (Ruanda, Etiópia, Senegal etc.) devem sofrer menos da crise sanitária e da degradação dos termos da troca. Na União Econômica e Monetária da África Ocidental e na Comunidade da África Oriental, o crescimento econômico deve permanecer positivo na medida em que os países dessas regiões apresentam um nível um pouco mais baixo de integração às cadeias de valor globais (WORLD BANK, 2020).

\section{A ameaça de uma explosão da dívida}

A evolução da dívida pública representa um risco suplementar para os países africanos. O período 2010-2018 já tinha sido caracterizado por um aumento da dívida, que passou de 40 para 59\% do PIB (WORLD BANK, 2019). Em 2018, a taxa de endividamento já tinha voltado para seu nível de 2000 e o serviço da dívida pago pelos países da região alcançou 35,8 milhões dólares (2,1\% do PIB).

Às causas estruturais do endividamento vem doravante se somar as importantes perdas de receitas sob o efeito da diminuição do crescimento econômico e crise do comércio exterior. Os governos reivindicarão linhas de financiamento que podem acelerar ainda mais o ritmo do crescimento da dívida. O financiamento de programas visando a enfrentar a pandemia e estimular o crescimento requerem, segundo o Banco Mundial, a injeção de 100 bilhões de dólares (WORLD BANK, 2020). Para isso, uma moratória sobre a dívida é apontada como uma solução para injetar liquidez nas economias nacionais e ampliar sua margem de manobra orçamentária. Até o presente momento, Banco Mundial e Fundo Monetário Internacional se limitaram a congelar a dívida.

\section{4 - Os possíveis impactos humanos e sociais do Coronavírus- COVID-19 na África subsaariana}

\section{O desafio humanitário da gestão dos campos dos refugiados e deslocados}

Entre os grupos mais expostos à contaminação intracomunitária pelo Coronavírus/ COVID-19 figuram os refugiados, deslocados e outras vítimas de conflitos e perseguições. No final de 2018, 26,4 milhões de pessoas viviam em espaços sob a competência do Alto Comissariado das Nações Unidas para os Refugiados (ANCNUR). 


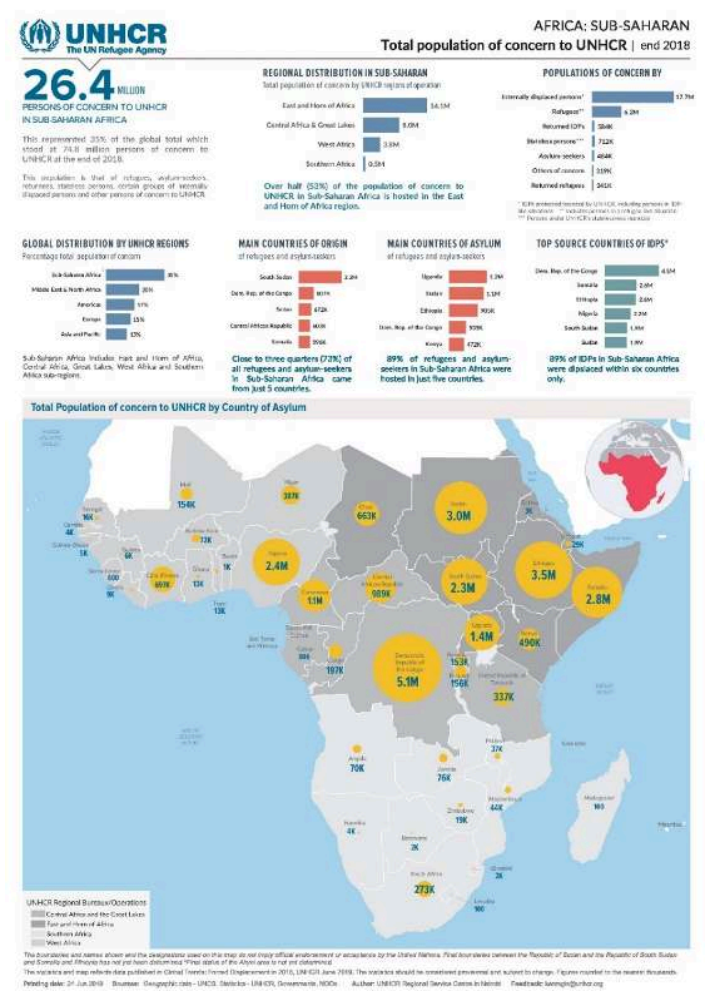

Fonte : UNHCR.

A gestão humanitária dos campos de refugiados e deslocados enfrenta cotidianamente dificuldades decorrentes da insuficiência de recursos financeiros, da instabilidade geopolítica, da precariedade das redes logísticas, das tensões internas, da escassez de água potável etc. Em tempos de pandemia, a elevada densidade populacional e a baixa imunidade de parte dos indivíduos podem facilitar a transmissão local do vírus entre os refugiados e deslocados. No Sudão do Sul, 200.000 pessoas vivem em campos superpovoados e sem acesso a instalações sanitárias corretas. As restrições à circulação das pessoas, que se impõem aos profissionais do setor humanitário, são suscetíveis de agravar ainda mais a situação prejudicando o acesso das agências da ONU e as ONGs aos campos.

\section{A problemática da insegurança alimentar}

O impacto da pandemia sobre as famílias africanas pode, também, ser considerável. A combinação de aumento do desemprego - 20 milhões de empregos formais estariam ameaçados; de retração das atividades informais, de aumento dos gastos em saúde, de inflação etc. ameaça os grupos sociais mais vulneráveis. Por sua parte, a desorganização dos circuitos de distribuição dos produtos agrícolas e o aumento dos custos de transação provocado pelas restrições à circulação podem agravar a insegurança alimentar nas regiões mais pobres (em particular no Sahel) e entre os segmentos mais frágeis da população. A situação no Chifre da África, que já sofre dos impactos de uma invasão de gafanhotos e do subdesenvolvimento dos mercados alimentares, pode se tornar trágica considerando que os programas humanitários são dificultados pelos 
conflitos e pela instabilidade geopolítica. A Somália é, neste sentido, o país mais exposto à uma degradação da situação alimentar.

Nos grandes centros urbanos, a questão do abastecimento alimentar pode revelar-se muito problemática num continente que importa aproximadamente $70 \%$ de seus alimentos de base. A recomendação da União Africana tem sido de estocar alimentos importados (em particular arroz e trigo), mas o crescimento brutal das importações pode gerar movimentos especulativos que, combinados aos efeitos da desvalorização de algumas moedas, da explosão da dívida pública e da queda do poder aquisitivo dos mais pobres, pode impactar a situação alimentar e sanitária de dezenas de milhões de Africanos. 0 fechamento das fronteiras internacionais à circulação humana questiona, do seu lado, a capacidade dos circuitos formais de transporte de alimentos de garantir o abastecimento alimentar em fluxos contínuos de cidades como Maputo (Moçambique) e de capitais do Sahel, que importam parte significativa de seus alimentos de países vizinhos. Nas cidades pequenas e médias, a prática muito comum da agricultura urbana por populações que circulam de forma extremamente flexível entre o campo e a cidade, pode limitar os impactos da pandemia.

\section{5 - A África pós-Coronavírus/COVID-19: lições, desafios e construção de alternativas}

Os períodos de grandes convulsões e pandemias são também momentos de reflexão e debates que apontam limitações, falhas e o caráter injusto dos sistemas, estruturas e ideias hegemônicos. Intelectuais seguindo o lema o mundo não será mais o mesmo apostam em bifurcações sociopolíticas, econômicas, culturais ou ideológicas. Apesar do estágio ainda inicial da difusão do Coronavírus na África subsaariana, intelectuais africanos já propõem pistas de reflexão relevantes para construir alternativas.

\section{Pandemia e capacidade de resiliência sanitária}

Em 2014, quando o primeiro caso de Ebola foi detectado em Lagos (20 milhões de habitantes), apostava-se numa catástrofe sanitária sem precedentes num ambiente urbano caracterizado por uma elevada densidade populacional, desigualdades socioespaciais extremas e estruturas sanitárias globalmente precárias. Apesar disso, a doença, altamente contagiosa, que matou 11.000 pessoas na África ocidental entre 2013 e 2016, teria contaminado somente 19 habitantes, entre os quais 7 faleceram (LE POINT AFRIQUE, 2020). As autoridades sanitárias da Nigéria tinham então demostrado uma elevada capacidade de resposta: realocação de recursos humanos de Abuja para Lagos, cooperação estreita com fundações e ONGs nacionais e internacionais, limitação da circulação etc. Hoje, apesar da permanência de inúmeros fatores críticos, o governo conseguiu estabelecer um sistema de vigilância, instalar laboratórios de detecção em diversas cidades e alguns centros de quarentena (Abuja, Lagos) (LE POINT AFRIQUE, 2020). Da mesma forma, na África do Sul, governo central e autoridades locais adotaram um amplo e sofisticado leque de medidas de prevenção.

o caso nigeriano ilustra $o$ fato que o continente africano tem demostrado historicamente uma capacidade de resiliência que permitiu mitigar os impactos de importantes surtos epidêmicos. O saber fazer acumulado nas últimas décadas pode, assim, ser mobilizado para gerir a atual crise sanitária. Por isso, alguns países adotaram 
imediatamente protocolos de urgência sanitária e medidas de confinamento quando foram detectados os primeiros casos de Coronavìrus nos seus territórios nacionais.

Um coletivo de 25 intelectuais africanos (Diagne, Sarr, Lopes, M’Bembe, Nubukpo etc.) destaca que as redes de solidariedade sociais de proximidade e a gestão familiar das doenças, que costumam compensar parcialmente as falhas dos aparelhos de Estado, podem mitigar os impactos sanitários e psicológicos da pandemia (COLETIVO, 2020). Além disso, o contexto político continental parece ser favorável a cooperação entre União Africana, autoridades sanitárias nacionais, agências internacionais (OMS), ONGs africanas e internacionais. A ação multilateral Africa Joint Continental Strategy for COVID-19 OUTBREAK ilustra esses esforços de cooperação transnacional, com destaque para a capacidade dos laboratórios, a prevenção e o controle nos centros médicos, a comunicação, a logística etc. (GÓMEZ DÍAZ; CRUZ MATA, 2020).

\section{As elites e os Estados: uma bifurcação das políticas de saúde pública?}

Num continente cujas elites políticas e/ou econômicas costumam frequentar hospitais da Europa ocidental, os investimentos públicos nos sistemas de saúde pública nacionais foram historicamente insuficientes. O ginecologista congolês Denis Mukwege (2020), Prêmio Nobel da Paz 2018, prevê uma mobilização da sociedade contestando aparelhos de Estado e estruturas tecnocráticas que devem reconhecer seus limites e suas falhas, conferindo maior protagonismo às comunidades locais, às autoridades costumeiras, à sociedade civil etc. para inventar novas formas de governança da saúde pública. 0 mesmo raciocínio se impõe, segundo ele, as políticas de desenvolvimento (MUKWEGE, 2020).

A ação da sociedade em contexto de pandemia é ressaltada por outros especialistas sinalizando que a mobilização de estruturas comunitárias locais tem se revelado eficiente na ocasião de pandemias anteriores. Para Ousmane Faye, diretor do Instituto Pasteur de Dacar (Senegal),

"o ensinamento do vírus ebola é que esta epidemia não constituiu um problema exclusivamente sanitário. Existe uma dimensão socioantropológica e de comunicação. A riposta deve ser comunitária. $\mathrm{O}$ mundo médico fornece as diretrizes, mas é a comunidade que se situa no centro da luta" (FAYE, 2020).

A mobilização capilar da sociedade permitiria, segundo ele, contextualizar localmente o caráter muito técnico da ciência moderna e as ações sanitárias decorrentes (FAYE, 2020).

\section{Do Consenso de Washington para o Consenso de Dacar?}

No campo da economia, o debate tem sido hegemonizado por uma "nova geração" de economistas que integrou Agências Internacionais nas últimas duas décadas. Uma retórica "pós-Programas de Ajuste Estrutural", propondo a combinação de economia de mercado, integração regional, novos modelos de governança, investimentos sociais, em novas tecnologias e em instituições de pesquisa e sustentabilidade ambiental, é amplamente divulgada pela literatura cinza, pelo próprio Banco Mundial e pela mídia continental e internacional.

O economista senegalês Papa Demba Thiam aponta que o Covid-19 evidenciou a vulnerabilidade de economias desenvolvidas que relocalizaram atividades estratégicas para países asiáticos e sofrem da dificuldade de reestruturar emergencialmente alguns 
segmentos industriais para produzir bens de baixa ou média complexidade tecnológica (máscaras, testes de deteç̧ão etc.) (DIAWARA, 2020). 0 mesmo pesquisador ressalta que o continente africano, por não dispor de estruturas produtivas tão complexas e rígidas, pode constituir um importante campo de Investimentos Produtivos Externos (IDEs) e se tornar uma fronteira de acumulação para um capitalismo mais disciplinado (DIAWARA, 2020). Segundo Thiam, a aplicação dos princípios do Consenso de Dacar (2019) permitiria promover modelos de desenvolvimento resilientes e inclusivos.

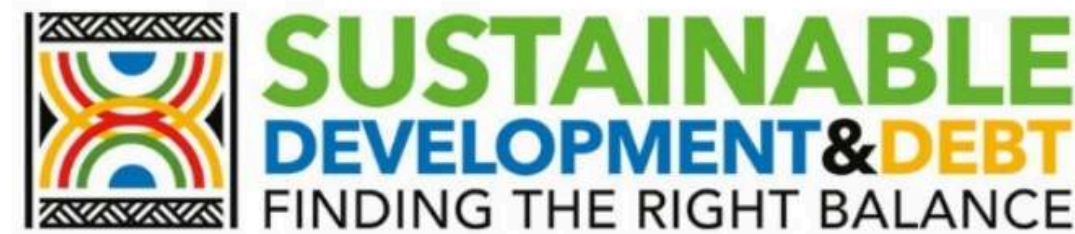

Dakar, Senegal

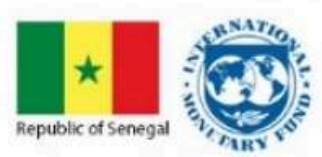

December 2, 2019

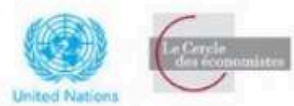

7 pontos do Consenso de Dacar:

Consolidar a mobilização de recursos internos fiscais e a poupança pública para financiar o desenvolvimento.

Melhorar a governança das finanças públicas e do ambiente de negócios.

Considerar o constrangimento imposto pela mudança climática e pelas despesas em matéria de segurança frente ao choque terrorista.

Frente a necessidade emergencial de investimentos na África, os parceiros do desenvolvimento devem levar em consideração o valor dos ativos na análise da viabilidade da dívida de cada país.

Lutar contra a troca desigual, notadamente a baixa remuneração das matérias primas e o déficit na criação de valores através da transformação local dos produtos.

Reestabelecer um olhar objetivo por parte das instituições internacionais sobre a percepção, hoje exagerada, do risco na África, percepção que pesa sobre a notação dos projetos de investimentos.

Estimular a colaboração entre os países do continente africano e os parceiros bilaterais e multilaterais, para uma governança financeira mundial mais equitativa e para que a África seja uma das locomotivas do crescimento mundial.

Numa perspectiva menos ortodoxa, o economista togolês Kako Nubukpo (2020) advoga em prol de uma ruptura sistêmica assinalando a fragilidade dos principais pilares da globalização e a crise do neoliberalismo. Para construir uma mundialização mais justa e ecologicamente viável, o professor Nubukpo propõe 3 emergências: 1) a mitigação dos impactos econômicos consequentes das rupturas de cadeias de abastecimento e da queda do preço das principais matérias primas e das receitas do turismo. Paralelemente, arbitragens orçamentárias devem garantir maiores fluxos de recursos para políticas sociais; 2) a ruptura definitiva com as políticas malthusianas das agências internacionais preconizando a austeridade orçamentária como instrumento de crescimento; 3) a construção de um paradigma endógeno de desenvolvimento valorizando circuitos curtos, economia solidária e de baixo carbono, uma articulação mais harmoniosa das redes de curto e longo alcance geográfica e a redistribuição socialmente mais justa das rendas (NUBUKPO, 2020). 
O coletivo de intelectuais africanos já citado (COLETIVO, 2020) se inscreve na mesma perspectiva de ruptura com um modelo de (sub)desenvolvimento pautado na exportação de commodities e, por isso, extremamente vulnerável aos choques exógenos. A atual emergência sanitária cria, segundo eles, uma oportunidade histórica de mobilização de recursos endógenos, das inteligências coletivas e da criatividade da juventude para romper com as economias de renta através da transformação local das matérias primas, vetor de criação de valor e empregos, e a diversificação da base produtiva (Coletivo, 2020).

\section{Tempos ainda mais sombrios para o Mundo e a África?}

Num texto sombrio, publicado na segunda semana do mês de abril de 2020, Achille M 'Bembe assevera que "em sua vertente noturna, a modernidade terá sido, do começo ao fim, uma guerra interminável travada contra o vivo. E ela está longe de terminar" (M 'BEMBE, 2020). O filósofo prevê que no plano geopolítico "a lógica da força e do poder continuará a prevalecer" e que "a divisão feroz do globo será acentuada e as linhas de segmentação serão intensificadas" (M'BEMBE, 2020). Segundo o mesmo autor, assistiremos a um aprofundamento dos nacionalismos, caracterizado por controles ainda mais rígidos das fronteiras, e a uma exacerbação das formas de contenção territorial, ao ponto que "a vida por trás das telas e nos enclaves protegidos por empresas de segurança se tornará a norma" (M'BEMBE, 2020).

No caso específico da África pós-Coronavírus/COVID-19, se intensificarão as dinâmicas predatórias de extração intensiva de energia, de vendas de terras, de destruição das florestas ou de pulverização agrícola. Os metais raros extraídos do subsolo da África central que integram a cadeia de valor dos chips e computadores são estratégicos demais para que sua produção seja civilizada (M'BEMBE, 2020). Paralelamente, a circulação dos Africanos será ainda mais restringida e controlada.

Para romper com as lógicas extrativistas predatórias, o racismo e as desigualdades estruturais e a aniquilação do meio ambiente, o intelectual camaronês propõe um direito universal a respiração extensível ao conjunto do vivo. Esse direito "não pode ser objeto de confisco e escapa à toda soberania em si mesmo. Trata-se, ademais, de um direito originário de habitar a Terra, próprio da comunidade universal de seus habitantes, humanos e outros" (M'BEMBE, 2020).

A tribuna publicada no semanal Jeune Afrique por Achille M'Bembe e 24 outros intelectuais apresenta, por sua parte, a pandemia como um fim da história suscetível de estimular a construção de modelos alternativos (COLETIVO, 2020). A África dispõe, segundo os autores, de um amplo leque de recursos, de uma mão-de-obra flexível e criativa, de profissionais formados para estabelecer as bases de

"uma nova consciência, conectando o continente às suas diásporas, suas novas redes de intelectuais, de profissionais, de pesquisadores, de militantes, de associações, de políticos, de independentes, suscetível de inserir vozes novas e disruptivas nesses debates" (COLETIVO, 2020).

É paradoxalmente no momento em que a pandemia de Coronavírus/COVID-19 "semeia a morte e a desolação nos países, perturba o funcionamento das sociedades mais consolidadas, altera os calendários políticos [que chega] para a África a hora de enfrentar seus desafios e reinventar as modalidades de sua presença no mundo" (COLETIVO, 2020). 


\section{Considerações finais}

A pandemia de Coronavírus/COVID-19 testa a capacidade de resiliência das sociedades, das economias e das culturas, particularmente nos países mais duramente atingidos. Incertezas pairam a respeito de possíveis novas feições da humanidade pós-pandemia. Estamos a caminho da exacerbação das políticas de controle totalitário-digital das populações, testadas com certo sucesso na China? Segundo Achille M’Bembe, o direito necropolítico de governos quem decidem quem viverá e quem morrerá, e de maneira as pessoas devem viver e morrer, adquire novas expressões com a pandemia de Coronavírus/COVID-19, que obriga autoridades políticas e sanitárias a definir quem " continuará respirando" (M'BEMBE, 2016; M'BEMBE, 2020). O necroliberalismo, postulando o descarte de quem não tem valor (BERCITO, 2020), pode ser anunciador de horizontes socioeconômicos e políticos funestos para a África subsaariana? No campo econômico, estamos diante de um aprofundamento da globalização predatória, agora sob liderança chinesa, ou, ao contrário, diante de um fenômeno de desglobalização beneficiando circuitos produtivos e logísticos mais curtos e mais sustentáveis?

$\mathrm{Na}$ África subsaariana, os efeitos humanos da crise pandêmica sobre as sociedades podem serem devastadores, considerando que regiões do mundo dotadas de estruturas e técnicas sanitárias sofisticadas foram duramente impactadas pela pandemia. 0 grau de exposição das populações em situação de maior vulnerabilidade social e sanitária pode se refletir num crescimento exponencial do número das vítimas do COVID-19. Até o presente momento (14/04/2020), os níveis de contaminação são ainda inferiores ao resto mundo, provavelmente em razão da subnotificação de casos. Por sua parte, os impactos econômicos já são severos para economias que dependem globalmente das exportações de commodities, do turismo internacional, das remessas oriundas da diáspora e dos investimentos em megaprojetos infra estruturais. Como a diminuição da demanda, a queda do preço das principais matérias primais e as novas lógicas de circulação do capital afetarão o continente africano num espaço econômico mundial em reestruturação?

Para diversos intelectuais africanos, os cenários mais pessimistas não participam de uma fatalidade histórica da qual o continente não poderia escapar. Ao longo da História, os períodos de crise se traduziram por importantes bifurcações paradigmáticas e civilizacionais, animadas pelo dinamismo de sociedades em busca de mudanças radicais, mudanças que alimentaram, por exemplo, a emergência ou a queda de impérios, transições hegemônicas etc. A tribuna de Jeune Afrique, assinada por esses intelectuais, aposta na construção de uma outra África numa humanidade onde compaixão, empatia, equidade e solidariedade definiriam as sociedades (COLETIVO, 2020). O continente é convocado a propor uma resposta potente, durável e racional para poder abandonar a Utopia e ingressar no espaço dos possíveis (Bourdieu). Segundo o economista togolês Nubupko "é paradoxalmente a hora para a África de assumir a mudança mostrando para o resto do mundo os vetores escondidos de sua resiliência." (NUBUKPO, 2020). 


\section{BIBLIOGRAFIA}

AFRICAN UNION. Impact of the Coronavirus Covid-19 on the African Economy. Adis Abeba: African Union, 2020.

AMREF - HEALTH AFRICA. Amref COVID-19 Africa Information Centre. https://amref.org/ coronavirus/?fbclid=IwAR0PyW_2ZX_DSCBLoeSgVq9gpn4YDapFkQ6qhWIBzSNt79oNmN8oCf6s2o.

BERCITO, Diogo. Pandemia democratizou poder de matar, diz autor da teoria da 'necropolítica'. Entrevista de Achille M’Bembe. Folha de São Paulo, São Paulo, 30.04.2020.

CABALLERO, Chema. Chinos, minería ilegal, empleo y armas en Ghana. El País, Madri, 26.06.2017.

CALDERON, Cesar; KAMBOU, Gerard; ZEBAZE DJIOFACK, Calvin; KORMAN, Vijdan; KUBOTA, Megumi; CANTU CANALES, Catalina. Africa's Pulse: An Analysis of Issues Shaping Africa's Economic Future. Washington, DC: World Bank, 2020.

COLETIVO [de 25 intelectuais africanos]. Tribune: Coronavirus : pour en sortir plus forts ensemble. Jeune Afrique, Paris, 10.04.2020.

DIAWARA, Malick. «Le Covid-19 peut aider les économies africaines à se réinventer». Entrevista de Papa Demba Thiam. Le Point Afrique, Paris, 31.02.2020.

FAYE Ousmane. Coronavirus: «Ne nous reposons pas sur l'idée que l'Afrique serait préservée par la jeunesse de sa population», Le Monde Afrique, Paris, 30.03.2020.

GÓMEZ DÍAZ Elena; CRUZ MATA Israel. Por qué preocupa tanto la pandemia de COVID-19 en África. The Conversation España, Madri, 01.04.2020.

HAAS Astrid R.N. Shaping Africa's urban areas to withstand future pandemics. The Conversation Africa, Braamfontein, South Africa, 01.04.2020.

HAESBAERT, Rogério: Entre a contenção e o confinamento dos corpos-território: reflexões geográficas em tempos de pandemia (I) e (II). AGB-Campinas, 24.03.2020. Disponível em: http:// agbcampinas.com.br/site/2020/rogerio-haesbaert-desterritorializacao-sem-limites-reflexoesgeograficas-em-tempos-de-pandemia-i/

HARVEY, David. Condição pós-moderna. São Paulo: Loyola, 1989

KUO, Lily. Drone photography captures the dramatic inequality of Nairobi. Quartz Africa, Nairobi, 25.11.2016.

LE POINT AFRIQUE. Le Nigeria, premier pays d'Afrique subsaharienne touché par le coronavirus. Le Point, Paris, 28.02.2020.

MABUKA-MAROA, Jenniffer. Few clinical trials are done in Africa: COVID-19 shows why this urgently needs to change. The Conversation Africa, Braamfontein, South Africa, 06.04.2020.

M’BEMBE, Achille. O direito universal a respiração. Texto (020). São Paulo: n1edições, 2020. https://n-1edicoes.org/textos-1

M'BEMBE, Achille. Necropolítica. Biopoder, soberania, estado de exceção, política da morte. Artes e ensaios, n. 32, pp. 123-151, 2016 
MONIÉ, Frédéric: Petróleo, desenvolvimento e dinâmicas espaciais na África subsaariana In: MONIÉ Frédéric, BINSZTOK Jacob (org.). Geografia e geopolítica do petróleo. Rio de Janeiro: Mauad X, pp. 201-236, 2012.

MUKWEGE, Denis. L'appel du prix Nobel de la paix Denis Mukwege: en Afrique, «il faut agir au plus vite si nous voulons éviter l'hécatombe». Le Monde Afrique, Paris, 28.03.2020.

MARTINEAU, Jean-Luc. Djibouti et le «commerce» des bases militaires: un jeu dangereux? L’Espace Politique [En ligne], n³4, 2018-1. Disponível em https://doi.org/10.4000/ espacepolitique.4719

NUBUKPO, Kako. «Après le coronavirus, une autre Afrique est possible et ce n'est pas une utopie», Le Monde Afrique, Paris, 04.04.2020.

O 'KEEFE, Brian. Mapping a contagion: how the coronavirus may spread around the world. Fortune, NYC, 17.022020.

POUYA, Léonard Pegwndé. Diffusion spatiale du Coronavírus au Burkina Fasso. Ougadougou, Miméo, 11.04.2020.

SANTOS, Milton. A cidade nos países subdesenvolvidos. Rio de Janeiro: Civilização Brasileira, 1965.

SANTOS, Milton. O espaço dividido: os dois circuitos da economia urbana dos países subdesenvolvidos. Rio de Janeiro: Francisco Alves, 1979.

SUN, X., SAMBA, T.T., YAO, J. et al. Impact of the Ebola outbreak on routine immunization in western area, Sierra Leone - a field survey from an Ebola epidemic area. BMC Public Health. $\mathrm{N}^{\circ} 17$, 2017.

TILOUINE, Joan. Coronavirus: «En Afrique, on ne réfléchira pas le développement de la même façon après la crise». Entrevista de Ibrahim Assane Mayaki. Le Monde Afrique, Paris, 10.04.2020.

TISSOT, Nathalie. En Afrique, face au coronavirus, «on constate des augmentations de prix et quelques pénuries». Entrevista de Vera Songwe, Le Monde Afrique, Paris, 17.03.2020.

VELTZ, Pierre. Mundialización, ciudades y territorios. Barcelona: Ariel, 1999.

WORLD BANK. Global Economic Prospects, January 2019: Darkening Skies. Washington, DC: World Bank, 2019

YONLIHINZA, Issa Abdou. Lorsque l'orpaillage pousse à l'exode depuis le cœur du Sahel. The Conversation, Paris, 14.05.2017.

\section{RESUMOS}

A pandemia global de COVID-19 vitimou os primeiros habitantes da África subsaariana no início do mês de março de 2020. Após a notificação dos primeiros casos de contaminação pelo Coronavírus, governos e autoridades sanitárias dos países africanos adotaram políticas, medidas e protocolos preventivos e médicos que testam a capacidade de resposta de estruturas de saúde pública consideradas globalmente precárias. Mas, o caráter estratégico da prevenção se depara com o imperativo de sobrevivência dos trabalhadores informais que representam a grande maioria da população ativa rural e urbana. Por sua parte, a economia formal, que já apresentava evidentes sinais de desaquecimento, pode ser impactada pela desorganização dos circuitos produtivos e logísticos mundiais e pela queda do preço das principais matérias primas. Insegurança alimentar e desemprego são suscetíveis de alcançar níveis alarmantes. No entanto, 
as sociedades subsaarianas têm demostrado no passado capacidades de resiliência que poderiam, no contexto atual, amenizar os efeitos do choque pandêmico. Do seu lado, intelectuais africanos questionam modelos de desenvolvimento, estruturas sociopolíticas e institucionais e relações Humanidade/Planeta impostos pela modernidade ocidental e debatem possíveis alternativas que fariam ingressar o continente no espaço dos possíveis.

The global pandemic of COVID-19 victimised the first inhabitants of sub-Saharan Africa in early March 2020. After announcing the first cases of contamination by Coronavirus, governments and health authorities in African countries adopted preventive and medical policies, measures and protocols that examine the response capacity of the public health structures, globally considered precarious. However, the strategic nature of prevention encounters with the survival needs of informal workers who represent the vast majority of the rural and urban active population. For its part, the formal economy, which had already showed evident signs of a slowdown, may be impacted by the disorganisation of the world's productive and logistical circuits and by the fall in the price of the primary raw materials. Food insecurity and unemployment are likely to reach alarming levels. Nonetheless, sub-Saharan societies have shown resilience capabilities in the past that could, in the current context, mitigate the effects of the pandemic shock. For their part, groups of African intellectuals question development models, socio-political and institutional structures and Humanity/Planet relations imposed by Western modernity and debate possible alternatives that would make the continent enter the space of possibles.

La pandémie globale de Coronavirus-COVID-19 a fait ses premières victimes en Afrique subsaharienne au début du mois de Mars 2020. Après la notification des premiers cas de contamination par le Coronavirus, gouvernements e autorités sanitaires des pays africains ont adopté des politiques, des mesures et des protocoles préventifs et médicaux qui testent la capacité de réponse de structures sanitaires considérées globalement précaires. Mais, le caractère stratégique de la prévention se heurte à l'impératif de survie des travailleurs informels, qui représentent la grande majorité de la population active, en milieux rural et urbain. Pour sa part, l'économie formelle, qui démontrait déjà des signes d'essoufflement, pourrait être durement éprouvée par la désorganisation des circuits productifs et logistiques mondiaux et par la chute du prix des principales matières premières. Insécurité alimentaire et chômage peuvent atteindre des niveaux alarmants. Pourtant, les sociétés subsahariennes ont déjà démontré par le passé des capacités de résilience qui pourraient, dans le contexte actuel, limiter les effets du choc pandémique. De leur côté, des intellectuels africains questionnent les modèles de développement, les structures sociopolitiques et institutionnelles et les relations Humanité/ Planète imposées par la modernité occidentale et débattent des alternatives qui permettraient à 1 'Afrique d'entrer dans l'espace des possibles.

La pandemia mundial de COVID-19 victimizó a los primeros habitantes del África subsahariana a principios de marzo de 2020. Después de la notificación de los primeros casos de contaminación por coronavirus, los gobiernos y las autoridades sanitarias de los países africanos adoptaron políticas, medidas y protocolos preventivos y médicos. que prueban la capacidad de respuesta de las estructuras de salud pública consideradas globalmente precarias. Sin embargo, el carácter estratégico de la prevención se enfrenta al imperativo de supervivencia de los trabajadores informales que representan a la gran mayoría de la población activa rural y urbana. Por su parte, la economía formal, que ya mostró signos evidentes de desaceleración, puede verse afectada por la desorganización de los circuitos productivos y logísticos del mundo y por la caída del precio de las principales materias primas. Es probable que la inseguridad alimentaria y el desempleo alcancen niveles alarmantes. Sin embargo, las sociedades subsaharianas han demostrado capacidades de resiliencia en el pasado que podrían, en el contexto actual, mitigar los efectos del choque pandémico. Por su parte, los intelectuales africanos cuestionan los modelos de desarrollo, 
las estructuras sociopolíticas e institucionales y las relaciones Humanidad / Planeta impuestas por la modernidad occidental y debaten las posibles alternativas que harían que el continente ingrese al espacio de lo posible.

\section{ÍNDICE}

Mots-clés: pandémie de Coronavírus; diffusion spatiale; impacts socioéconomiques; Afrique subsaharienne

Keywords: Coronavirus pandemic, spatial diffusion; socio-economic impacts; Sub-Saharan Africa.

Palabras claves: pandemia de Coronavirus/COVID-19; difusión espacial; impactos socioeconómicos; África subsahariana

Palavras-chave: pandemia de Coronavírus/COVID-19; difusão espacial; impactos socioeconômicos; África subsaariana

\section{AUTOR}

\section{FRÉDÉRIC MONIÉ}

Doutor em Geografia, Universidade de Paris III; Professor Associado do Departamento de Geografia e Programa de Pós-Graduação em Geografia (PPGG) da Universidade Federal do Rio de Janeiro. Contato: frederic.rj@gmail.com. 